\title{
Multiple satellite observations of cloud cover in extratropical cyclones
}

\author{
Catherine M. Naud, ${ }^{1}$ James F. Booth, ${ }^{1}$ Derek J. Posselt, ${ }^{2}$ and Susan C. van den Heever ${ }^{3}$ \\ Received 1 April 2013; revised 1 August 2013; accepted 6 August 2013; published 9 September 2013.
}

[1] Using cloud observations from NASA Moderate Resolution Imaging

Spectroradiometer, Multiangle Imaging Spectroradiometer, and CloudSat-CALIPSO, composites of cloud fraction in southern and northern hemisphere extratropical cyclones are obtained for cold and warm seasons between 2006 and 2010, to assess differences between these three data sets, and between summer and winter cyclones. In both hemispheres and seasons, over the open ocean, the cyclone-centered cloud fraction composites agree within $5 \%$ across the three data sets, but behind the cold fronts, or over sea ice and land, the differences are much larger. To supplement the data set comparison and learn more about the cyclones, we also examine the differences in cloud fraction between cold and warm season for each data set. The difference in cloud fraction between cold and warm season southern hemisphere cyclones is small for all three data sets, but of the same order of magnitude as the differences between the data sets. The cold-warm season contrast in northern hemisphere cyclone cloud fractions is similar for all three data sets: in the warm sector, the cold season cloud fractions are lower close to the low, but larger on the equator edge than their warm season counterparts. This seasonal contrast in cloud fraction within the cyclones warm sector seems to be related to the seasonal differences in moisture flux within the cyclones. Our analysis suggests that the three different data sets can all be used confidently when studying the warm sector and warm frontal zone of extratropical cyclones but caution should be exerted when studying clouds in the cold sector.

Citation: Naud, C. M., J. F. Booth, D. J. Posselt, and S. C. van den Heever (2013), Multiple satellite observations of cloud cover in extratropical cyclones, J. Geophys. Res. Atmos., 118, 9982-9996, doi:10.1002/jgrd.50718.

\section{Introduction}

[2] Midlatitude clouds have been the object of greater scrutiny in recent years in part because most of the general circulation models that participated in the Coupled Model Intercomparison Project phase 3 (CMIP3) have an excess in solar absorption in the southern oceans [Trenberth and Fasullo, 2010]. There is evidence that this problem comes from an underestimate in cloud cover, in a region where clouds associated with extratropical cyclones have the largest shortwave cloud radiative effect [Haynes et al., 2011]. In fact, Bodas-Salcedo et al. [2012] and Williams et al. [2013] find that regional and climate models have difficulty representing cloud cover in southern hemisphere extratropical cyclones. Although relatively recent large-scale cloud-resolving simulations have demonstrated some success in the representation of northern hemisphere extratropical cyclones in case study mode [Igel et al., 2013], their representation in general

\footnotetext{
${ }^{1}$ Department of Applied Physics and Applied Mathematics, Columbia University, New York, New York, USA.

${ }^{2}$ Atmospheric, Oceanic and Space Sciences, University of Michigan, Ann Arbor, Michigan, USA.

${ }^{3}$ Department of Atmospheric Science, Colorado State University, Fort Collins, Colorado, USA.

Corresponding author: C. M. Naud, Columbia University, 2880 Broadway, New York, NY 10025, USA. (cn2140@columbia.edu)

C2013. American Geophysical Union. All Rights Reserved. 2169-897X/13/10.1002/jgrd.50718
}

circulation models is also problematic [e.g., Field et al., 2008; Naud et al., 2010; Booth et al., 2013].

[3] Our understanding of this problem has improved over the past 10 years due to the vast number of cloud observations provided by the NASA Earth Observing System (EOS) satellite program, which facilitates the examination of extratropical cyclones clouds. Following the work of Lau and Crane [1995], Klein and Jakob [1999], or Tselioudis and Jakob [2002], who composited cloud observations based on specific atmospheric conditions, Field and Wood [2007] utilized daily cloud fraction observations to study clouds in the warm conveyor belts of extratropical cyclones, by averaging the observations in a cyclone-centered region. These cyclone-centered composites allow the colocation of large-scale features and provide an average picture of the more salient features within cyclones. Govekar et al. [2011] used a similar technique to explore the three-dimensional structure of clouds in southern hemisphere extratropical cyclones. This method has also been used to evaluate a GCM's moisture and precipitation in midlatitude cyclones [Bauer and Del Genio, 2006], a GCM's cloud distribution [Field et al., 2008, 2011], as well as to help diagnose the cause of various models deficiencies [e.g., Bodas-Salcedo et al., 2012; Booth et al., 2013]. However, these studies of observed and modeled cyclonecentered composites of cloudiness are usually focused on a single observational data set. There has been little analysis of the differences across different cloud retrieval data sets for cyclone-centered composites. 
[4] With the increasing use of satellite-based composites as a tool for constraining numerical models, it has become essential to explore how differences in observing systems affect cyclone-centered composites. Therefore, we examine composites of total cloud fraction that are obtained from three different cloud data sets with the goal of illuminating such differences: (1) Terra and Aqua Moderate Resolution Imaging Spectroradiometer (MODIS) [Salomonson et al., 1989] daily products [Ackerman et al., 2008], (2) Multiangle Imaging Spectroradiometer (MISR) [Diner et al., 1998] daily (daytime only) Cloud Fraction by Altitude (CFbA) product [Di Girolamo et al., 2010], and (3) the combined active instruments CloudSat [Stephens et al., 2002] and Cloud-Aerosol Lidar and Infrared Pathfinder Satellite Observation (CALIPSO) [Winker et al., 2009] Geometric Profile (GEOPROF)-Lidar product [Mace et al., 2009]. These three data sets differ in their radiometric, geometric, and spatial view of clouds and should exhibit some differences in cloud fractions according to their inherent strengths and weaknesses [e.g., Marchand et al., 2010].

[5] Recently, instrument simulators have been introduced [Bodas-Salcedo et al., 2011] that transform model outputs into observation-like fields by taking into account measurement uncertainties and known weaknesses in retrievals. These simulated "observations" overcome some of the limitations in the observations discussed above, but they themselves rely on assumptions that may affect their accuracy [Mace et al., 2011; Pincus et al., 2012]. Besides not all modeling teams provide outputs processed with the simulators (e.g., reanalysis does not). Consequently, it is relevant to examine the possible errors in observed cyclone-centered composites of retrieved cloud products. Another motivation is that it is unclear how an average over many cyclones will differ for the different satellite retrievals given their various ranges in swath size, timing, and retrieval type and accuracy. Unfortunately, there are no cloud observations of sufficient known quality available over the entire midlatitudes, so the absolute error in MODIS, MISR, and CloudSat-CALIPSO cyclone-centered cloud cover cannot be quantified. However, a comparison of these three data sets can provide information as to how confident we can be in observed cyclone-centered cloud composites.

[6] Because cloud cover in extratropical cyclones is not strictly identical in both hemispheres, in part because the southern hemisphere cyclones have lower moisture content [e.g., Naud et al., 2012], we will perform our data set intercomparison separately for southern and northern hemisphere cyclones. In addition, moisture availability in both hemispheres changes with the seasons, but the changes differ for the northern and southern hemisphere. Therefore, we examine the seasonal variations in cyclone-centered cloud fractions. This analysis serves two purposes: (1) to show how disagreements between the three data sets can affect our ability to assess the cloud fraction differences, and (2) to determine the contrasts between cyclone clouds in the warm and cold season for both hemispheres.

\section{Data and Method}

[7] In this section, we describe the data sets and methods that are used to create cyclone-centered composites of cloud, sea ice, precipitable water, and winds for oceanic extratropical cyclones. Our examination uses both level-2 and level-3 satellite products. Retrieved products that are available at the native spatial and temporal resolution of the instrument are usually referred to as "level-2" products. When these level-2 products are combined into new products of lower temporal and spatial resolutions (e.g., $1^{\circ}$ grid, daily), these are referred to as "level3" products. The period chosen for our study is from November 2006 to September 2010, based on the availability of observations from active instruments.

\subsection{MODIS}

[8] The MODIS instruments are on both the NASA Terra (launched in 1999) and Aqua (launched in 2002) platforms. MODIS observes the Earth with 36 channels from 0.4 to $14 \mu \mathrm{m}$, with spatial resolution that varies from $250 \mathrm{~m}$ to $1 \mathrm{~km}$, on a polar orbit with a repeat time of 16 days and a swath width of $2330 \mathrm{~km}$. Cloud products are retrieved [Platnick et al., 2003] and collected in MOD06 and MYD06 files (for Terra and Aqua respectively), for the level- 2 products. The level-2 products are available in $5 \mathrm{~min}$ files along the orbit. Daily files are also available (MOD08_L3 and MYD08_L3) that accumulate observations of clouds and their properties in a $1^{\circ} \times 1^{\circ}$ grid every $24 \mathrm{~h}$. Here we use data from collection 51 (a collection number refers to the version of the processing algorithms used for the entire mission, " 51 " is the latest available for MODIS at the time of this study).

[9] Cloud fractions are extracted from the level-2 files and the daily level-3 files. The cloud fractions are calculated in a $5 \mathrm{~km} \times 5 \mathrm{~km}$ pixel, using the $1 \mathrm{~km}$ resolution cloud mask (MOD35/MYD35 files [Ackerman et al., 2008]). These cloud fractions are available both day and night, but the files also provide the daytime only cloud fractions. The cloud mask can successfully detect clouds that have an optical thickness of at least 0.4 . However, the mask does tend to: (1) overestimate by $5-7 \%$ cloud detections as scan angle increases (i.e., toward the edges of the swath [Ackerman et al., 2008]), (2) underestimate cloud detections in polar regions at night by up to $20 \%$ against 5\% during the daytime [Ackerman et al., 2008], and (3) overestimate cloud detections by $2 \%$ in the trade wind cumulus regions [Zhao and Di Girolamo, 2006].

\subsection{MISR}

[10] The MISR instrument, onboard Terra, observes the Earth with nine different cameras at Nadir and off Nadir $\left( \pm 26.1^{\circ}, \pm 45.6^{\circ}, \pm 60^{\circ}\right.$, and $\left.\pm 70^{\circ}\right)$ and at four different wavelengths $(0.446,0.558,0.672$, and $0.867 \mu \mathrm{m})$. The swath width is about $360 \mathrm{~km}$. Daily daytime-only cloud fractions are available in the Cloud-Fraction-by-Altitude files (CFbA) [Di Girolamo et al., 2010]. They are available either as a function of height in $500 \mathrm{~m}$ thick layers, or as a total cloud fraction for the entire atmospheric column, both on a $0.5^{\circ} \times 0.5^{\circ}$ grid. Here we use the total cloud fraction.

[11] The radiometric camera-by-camera cloud mask (RCCM) [Zhao and Di Girolamo, 2004] is the cloud masking algorithm used to calculate the cloud fractions in the $\mathrm{CFbA}$ files. This cloud mask uses radiometric thresholds for the red channel for all nine cameras. The $\mathrm{CFbA}$ cloud fractions are calculated using the RCCM for the nadir camera by default. If the nadir camera is affected by sunglint, off-nadir cameras may be used instead. The thresholds are not valid for sea ice or snow over land and are distinct between land and ocean. The uncertainties were estimated 
to be less than $2 \%$ over ocean and $7 \%$ over land [Di Girolamo et al., 2010]. To isolate areas where sea ice may be present, daily mean sea ice concentrations are used. If sea ice occurs at a given location at least 4 days during one month, this location is considered affected by sea ice for the entire month. When sea ice is detected, another cloud mask is used instead [Diner et al., 1999], i.e., either the Angular Signature Cloud Mask (ASCM) [Di Girolamo and Wilson, 2003] or the Stereo-derived Cloud Mask (SDCM) [Moroney et al., 2002]. Consequently, intermediate months will see an overestimate in sea ice concentration, and a larger occurrence of ASCM or SDCM is used in place of RCCM. The online quality statement of MISR cloud products (http://eosweb.larc.nasa. gov/PRODOCS/misr/Quality_Summaries/L2 Cloud Products. html) suggests that cloud fractions will be underestimated in regions where sea ice is mistakenly diagnosed. Another problem that usually affects radiometric cloud masks is that they may be missing optically thin clouds [e.g., Marchand et al., 2010]. Finally, MISR-derived cloud fractions may be overestimated by up to $20 \%$ in regions where cumuli may be present [Zhao and Di Girolamo, 2006]. Therefore, we take these limitations into consideration when interpreting the results.

\subsection{CloudSat-CALIPSO}

[12] The combined CloudSat-CALIPSO cloud profiles collected in the GEOPROF-LIDAR files are used here. There are no level-3 daily data available at the time of this study, so we use instantaneous level-2 observations. These files provide cloud base and top heights of up to five cloud layers in $2.5 \mathrm{~km}$ wide columns along the CloudSat orbit. The cloud base and top heights are obtained either from the CloudSat reflectivities and/or the coincident CALIPSO cloud detections within these $2.5 \mathrm{~km}$ wide columns. We create a cloud mask of $250 \mathrm{~m}$ vertical resolution and $2.5 \mathrm{~km}$ horizontal resolution using these cloud layer boundary locations. Because the CloudSat field of view is narrow, sampling of cloudiness in cyclones may be limited (in comparison with the other instruments). This limited coverage implies that some fixed locations on Earth may never be observed. However, since cyclones travel during their lifetime, there should be no systematic undersampled region within the cyclones, and with sufficient events included in our data set, full coverage will be achieved. This will be further discussed in section 3 .

[13] One strength of this combination of instruments for cloud detection is its high sensitivity to optically thin clouds provided by the CALIPSO lidar. One weakness that can affect cloud detections is that the radar suffers from a strong return close to the surface that makes it unable to reliably detect clouds in the first $1200 \mathrm{~m}$ above the surface [Marchand et al., 2008]. This surface clutter causes artificially large reflectivities, which can then be assumed to be caused by clouds. This is taken into account in the radar-only cloud mask, which limits false detections to less than $5 \%$. This is also partially compensated for by the coincident lidar observations when no higher level opaque clouds attenuate the lidar signal. Nevertheless, cloud fractions may be overestimated in regions where no or only low-level clouds are present. In this paper, we consider as cloudy any profile that contains at least one cloud layer even if its cloud top is below $1200 \mathrm{~m}$.

\subsection{Other Data Sets}

[14] Daily sea ice concentration data [Cavalieri et al., 1996] were obtained from the National Snow and Ice Data Center (NSIDC). These data are based on passive microwave brightness temperatures measured with the Nimbus-7 Scanning Multichannel Microwave Radiometer (SMMR), the Defense Meteorological Satellite Program (DMSP) Special Sensor Microwave/Imagers (SSM/I), and the DMSP-F17 Special Sensor Microwave Imager/Sounder (SSMIS). These data are available in a polar stereographic grid of $25 \mathrm{~km} \times 25 \mathrm{~km}$ resolution centered on the South and North poles. We use the "final data" product, which uses both SMMR and SSM/I observations and is released with a one year latency by the Goddard Space Flight Center and distributed by NSIDC. These observations are used here to determine the frequency of occurrence of sea ice within extratropical cyclones. We also use the land mask from these files.

[15] Precipitable water vapor (PWV) is retrieved over the ice-free oceans [Wentz and Meissner, 2004] using the Advanced Microwave Scanning Radiometer (AMSR-E) [Kawanishi et al., 2003] onboard Aqua and available in level-2 files since the beginning of the mission until its irremediable technical failure in October 2011.

[16] The NASA Modern Era Retrospective-analysis for Research and Applications (MERRA) [Rienecker et al., 2011] produces horizontal winds in a $0.5^{\circ} \times 0.667^{\circ}$ grid every $6 \mathrm{~h}$. Here we use the $850 \mathrm{hPa}$ winds to examine lowlevel cyclone circulation.

\subsection{Method}

[17] In this study, we focus on cloud fractions within extratropical cyclones that occurred between 2006 and 2010 between $30^{\circ}$ and $60^{\circ} \mathrm{S} / \mathrm{N}$ over the oceans. The locations of these cyclone centers are obtained from the NASA Modeling, Analysis, and Prediction (MAP) Climatology of Midlatitude Storminess database (MCMS) [Bauer and Del Genio, 2006], which detects, locates, and tracks cyclones globally using the European Center for Medium Range Weather Forecasts Interim reanalysis (ERA-interim) [Dee et al., 2011] sea level pressure fields. These cyclone locations are available every $6 \mathrm{~h}$, i.e., we use the term cyclone to refer to $6 \mathrm{~h}$ snapshots of the storms. The cyclones are further partitioned into two subsets based on season: cold (warm) season cyclones occur between May and September while warm (cold) season cyclones occur between November and March for the southern (northern) hemisphere. We have added a month on both sides of the typical three-month winter and summer designations to increase the cyclone sample size. This is necessary to compensate for the narrower swaths of MISR and CloudSat-CALIPSO.

[18] For each cyclone, for those cloud data that are available in daily files (i.e., MODIS and MISR), we extract same day cloud fractions within a $25^{\circ}$ distance from the cyclone centers. This means that there may be a delay of up to $24 \mathrm{~h}$ between the cloud and cyclone center detections. The impact of this potential delay on the cloud fraction attribution to the cyclones is discussed in section 3 .

[19] For cloud data that are available at the level-2 (i.e., CloudSat-CALIPSO, MODIS), we collect cloud fractions for each cyclone if the cloud observations were available within $25^{\circ}$ and $3 \mathrm{~h}$ of the cyclone center detection. This 

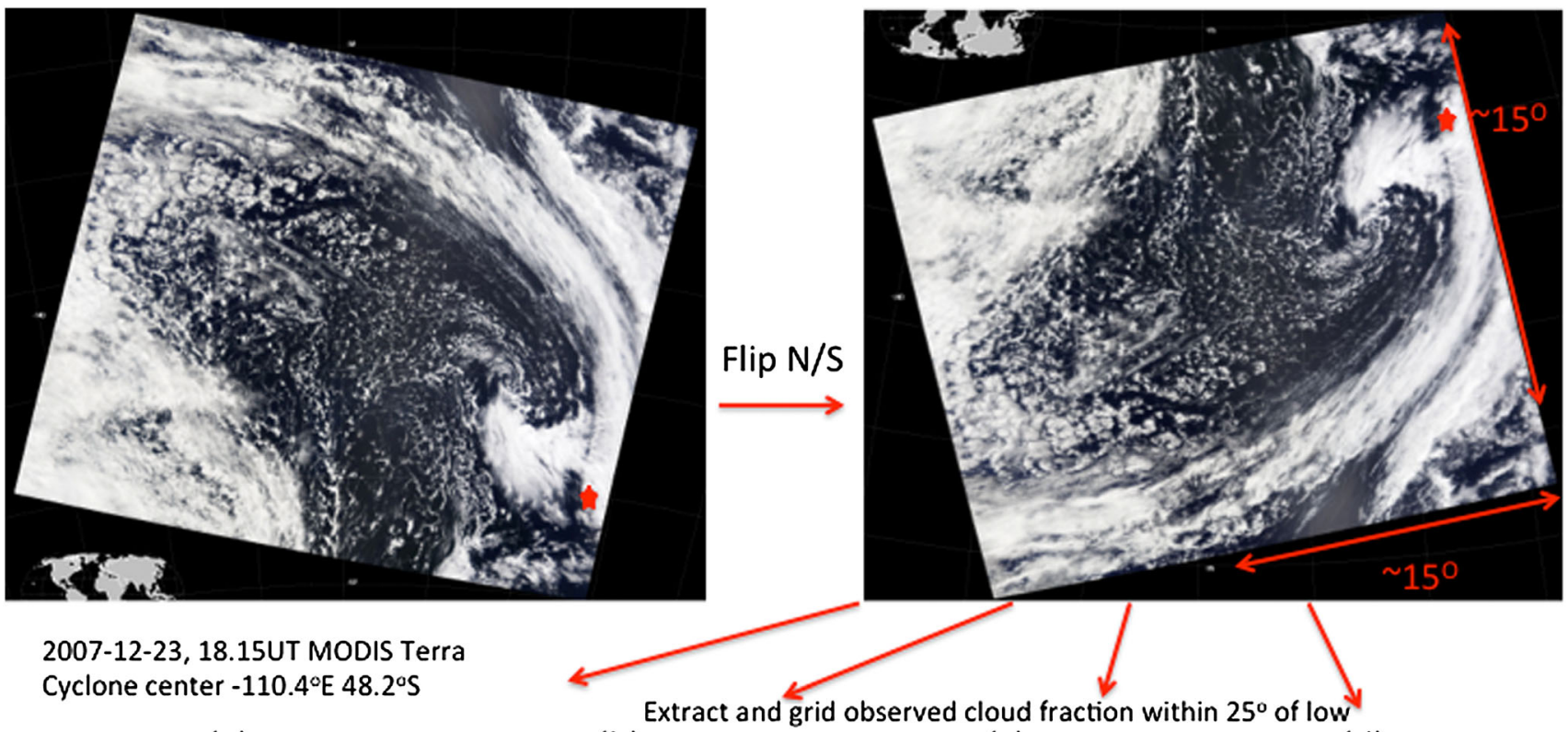

2007-12-23, 18.15UT MODIS Ter
Cyclone center $-110.4^{\circ} \mathrm{E} 48.2^{\circ} \mathrm{S}$

(a)

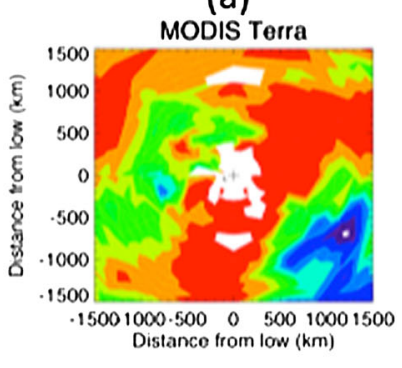

(b)

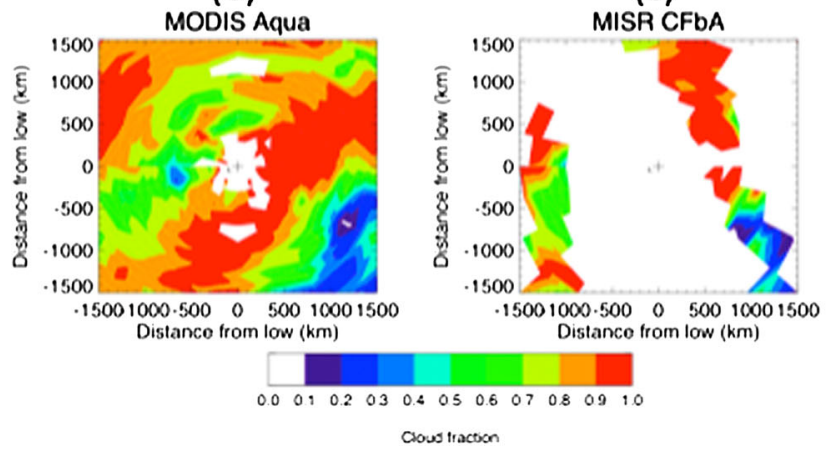

(d)

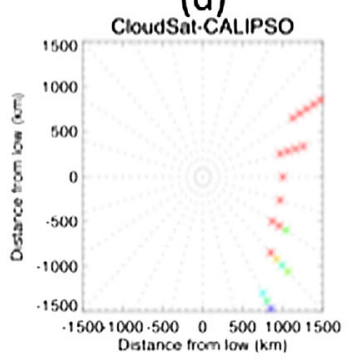

Figure 1. Schematic of method used to extract cloud observations for one cyclone found in the MCMS data set on 23 December 2007, $18 \mathrm{UT}, 48.2^{\circ} \mathrm{S}-110.4^{\circ} \mathrm{E}$ : (top left corner) MODIS-Terra true-color 18.15UT image (courtesy of http://modis-atmos.gsfc.nasa.gov/IMAGES/index_mod021 km.html), (top right corner) same image flipped along the north-south direction (the red star indicates the approximate position of the low pressure center), and cyclone-centered gridded cloud fractions around the cyclone from (a) MODIS-Terra daily, (b) MODIS-Aqua daily, (c) MISR CFbA daily, and (d) CloudSat-CALIPSO GEOPROF-LIDAR for 20.12UT orbit \#08803.

implies that some cyclones will not have near-coincident cloud observations and will not be included in our composites. While most cyclones are included in the MODIS and MISR composites $(21,998$ and 21,565 cyclones, respectively, for the southern hemisphere), between $25 \%$ and $30 \%$ of the cyclones, depending on location, are included in the CloudSatCALIPSO composites (6080 in total). When using only daytime data, MODIS composites still include around 20,000 cyclones for the southern hemisphere because of the wide swath, while CloudSat-CALIPSO cyclones are reduced to around 3000. Again, the impact will be discussed in section 3.

[20] Cloud fractions are averaged for each cyclone in a cyclone-centered stereographic grid (of $100 \mathrm{~km}$ radial and $14.4^{\circ}$ polar resolution), then all cyclone grids are averaged together, although separately for $\mathrm{SH}$ and $\mathrm{NH}$ cold and warm seasons. For comparison with NH cyclones, following Field and Wood [2007], we flip the SH cyclone composite plots, so that the poleward/southern side of the cyclones is at the top of the figure. This has no impact on our results. Unless otherwise stated, no rotation is applied to these composites. This is the same technique used by Field and Wood [2007] and differs from that of Naud et al. [2012] who rotate the composites to align the warm fronts, or Catto et al. [2010] who align the cyclones along their direction of propagation. Sea ice concentration, land fraction, $\mathrm{PWV}$, and $850 \mathrm{hPa}$ horizontal winds are composited in the same way as the cloud data.

[21] An example is given of a cyclone detected at $-48.2^{\circ} \mathrm{S}$ and $-110.43^{\circ} \mathrm{E}$ on 23 December 2007 at $18 \mathrm{UT}$ in the MCMS database (Figure 1). The true-color image obtained by MODIS-Terra is shown as well as the cloud fractions from MODIS (Terra and Aqua), MISR, and CloudSat-CALIPSO that were available for this cyclone. As the swath width of each instrument is different, the cloud fraction information is not necessarily available for the entire cyclone, i.e., MODIS cloud fractions cover most of the cyclone area, while MISR only observes two bands on each side of the low, and CloudSat-CALIPSO a narrow line to the east of the cyclone center for this case. 
(a) MODIS

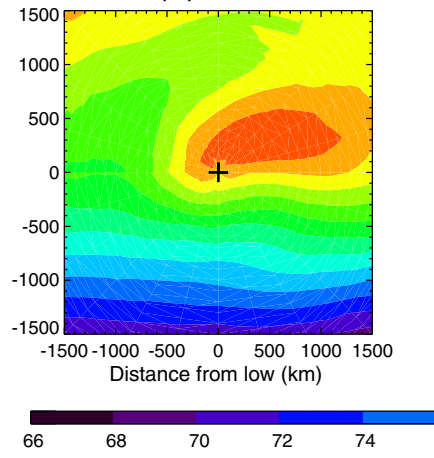

(b) MISR

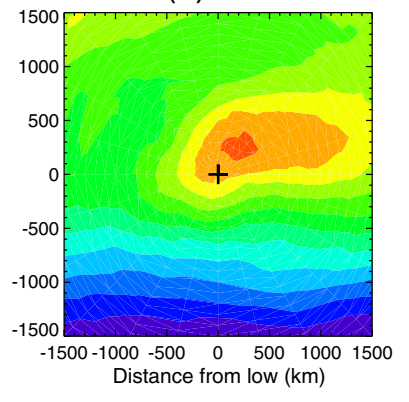

(c) Cloudsat-CALIPSO

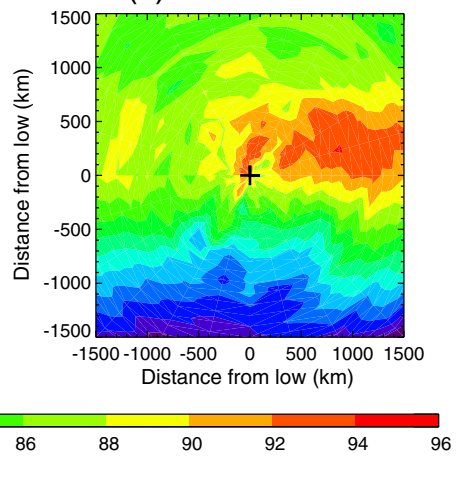

Figure 2. Cyclone-centered composite of cloud fraction for 2007-2010 cold season (MJJAS) SH cyclones obtained with daytime (a) MODIS-Terra daily, (b) MISR CFbA daily, and (c) CloudSatCALIPSO level-2 products. The + indicates the position of the minimum in sea level pressure.

[22] The MISR instrument only operates in the visible, and thus no observations are available on the nighttime portions of the orbits. For consistency, we also select MODIS and CloudSat-CALIPSO data where the solar zenith angle is less than $81.4^{\circ}$ (as imposed for MODIS daytime products). The same filter is applied to the ancillary data sets presented in section 2.4. We will discuss later differences between the MODIS and CloudSat-CALIPSO data sets when all orbits (day and night) are included.

\section{Cyclone-Centered Composites of Cloud Fraction: Impact of Method}

[23] In this section, we introduce the cyclone-centered composites of cloud fraction and analyze the uncertainties associated with our methods. To begin, we show the results for the cyclone composite for the SH cold season. Then, to quantify the observational uncertainties within the data sets, we examine how the cyclone composites are affected by: (a) a different platform (i.e., MODIS-Terra versus MODISAqua), and (b and c) the temporal and spatial resolutions of the cloud observations.

\subsection{Cloud Fraction Composites for SH Cold Season}

[24] To introduce the cyclone-centered composites of cloud fraction, we show results for the SH cold season. As mentioned above, SH cold season includes May to September, from 2007 to 2010, and the composites have been flipped along the north-south direction so that the pole is at the top of the figure and the equator at the bottom. Only daytime observations are used for Terra-MODIS and CloudSat-CALIPSO.

[25] Figure 2 represents the mean cyclone-centered cloud fractions for SH cold season cyclones using daytime MODISTerra daily, MISR CFbA daily, and CloudSat-CALIPSO instantaneous observations. For the three data sets, the main features are similar. The largest cloud fractions (greater than $90 \%$ ) occur on the poleward and eastern side of the cyclone center, extending about $1500 \mathrm{~km}$ east and $500 \mathrm{~km}$ poleward of the center. This area coincides with the warm frontal region. However, cold frontal clouds do not have a signature in these composites because cold fronts do not have a position as localized as the warm front, since they move from west to east with respect to the position of the low as the cyclones evolve. Thus, lower cloud fractions occur on (a) MODIS

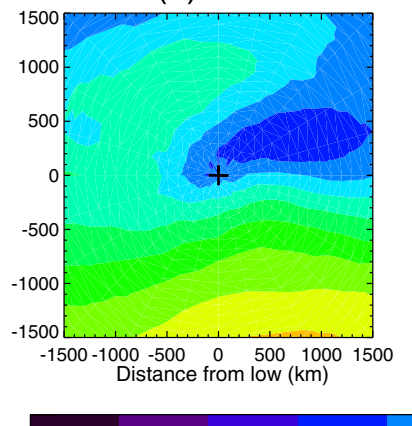

(b) MISR

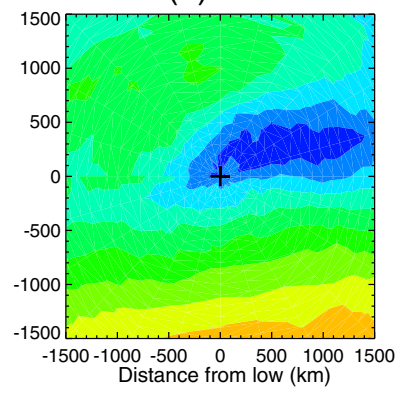

(c) Cloudsat-CALIPSO

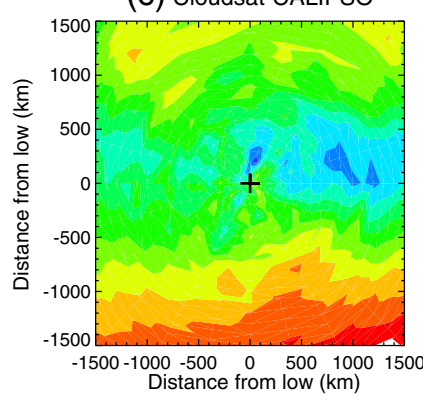

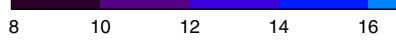

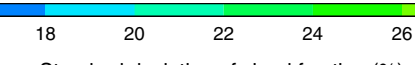

Standard deviation of cloud fraction (\%)

Figure 3. Cyclone-centered composite of standard deviation of (a) MODIS-Terra, (b) MISR CFbA, and (c) CloudSat-CALIPSO cloud fraction for SH cold season cyclones. 
(a) MODIS

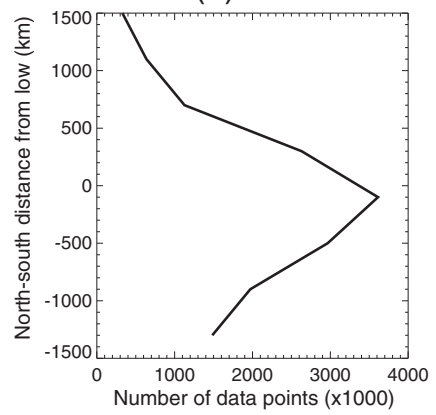

(b) MISR

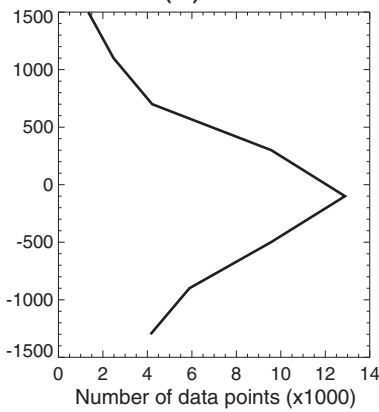

(c) CloudSat-CALIPSO

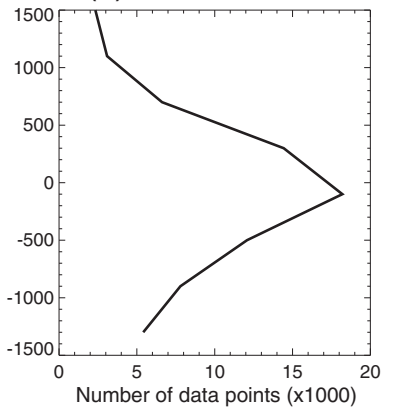

Figure 4. Total number of observations included in the Figure 2 composites along the north-south direction about the low and summed along the east-west direction about the low for (a) MODIS-terra, (b) MISR CFbA, and (c) CloudSat-CALIPSO.

the equator side of the low, as cold frontal cloudiness in one cyclone can be averaged with predominantly clear areas associated with the dry intrusion at the back of the cold front in another [e.g., Carlson, 1980].

[26] The composite standard deviation of the cloud fractions (Figure 3) is large in the region equatorward of the low center, where the cold fronts fail to overlap. The standard deviations increase as the instruments coverage decreases (c.f. Figure 1). Meanwhile, the standard deviation has a minimum in the warm frontal zone for all three data sets, suggesting that the composite results for this region are more robust (Figure 3).

[27] Next, we report on the total number of observations per composite for each data set (Figure 4). Also, since the values were nearly constant with respect to longitude, we show the zonal sums. There are more observations in the MODIS data set, due to the much larger swath than both MISR and CloudSat-CALIPSO, which allows near complete spatial coverage of all cyclones. The MISR cloud fractions are obtained at a $17.6 \mathrm{~km}$ resolution, which is much lower than either of the other two data sets, thus making the number of observations the lowest of the three. However, the distribution of observations is very similar between the three data sets, with more points near the cyclone centers, slightly less on the equator side and a steeper decrease toward the pole as in the SH cold season, the daytime observations become sparse south of $60^{\circ} \mathrm{S}$.

\subsection{MODIS Terra Versus Aqua}

[28] MODIS-Terra and MODIS-Aqua are compared in this study because MISR is onboard Terra and CloudSat and CALIPSO are less than a minute apart from Aqua. We therefore compared MODIS cloud fraction composites when obtained with the Terra versus Aqua instrument. For this comparison, we only consider daytime observations. Figure 5 shows the difference in cyclone-centered composites of cloud fraction between MODIS-Terra and MODISAqua for the two hemispheres and seasons (as defined in section 2.5; also, recall that the $\mathrm{SH}$ composites are flipped along the north-south direction). Differences between the two platforms are small, within $2 \%$ for $\mathrm{SH}$ cold, $\mathrm{NH}$ cold and $\mathrm{NH}$ warm seasons, and no larger than $3 \%$ for $\mathrm{SH}$ warm season. These differences are of a similar magnitude when we include both day and nighttime orbits. In light of these small differences, we arbitrarily chose to use MODIS-Terra when comparing the three data sets of interest here.

\subsection{Uncertainties Due to the Method}

[29] As discussed in section 2, the three satellite data sets differ in their temporal and spatial coverage. Here we work to quantify the impacts of these differences using MODIS. We take advantage of the fact that MODIS is available as both a daily and an instantaneous product, and it has a spatial coverage that can be conditioned to resemble the other data sets. For this evaluation, because we only use the MODIS data sets, we include both day and night observations, to include a larger number of observations.

[30] First, we assess the impact of using MODIS daily files instead of instantaneous (level-2) files, by comparing composites that use the two types: daily (level-3) versus instantaneous (level-2). Because of the large size of the MODIS
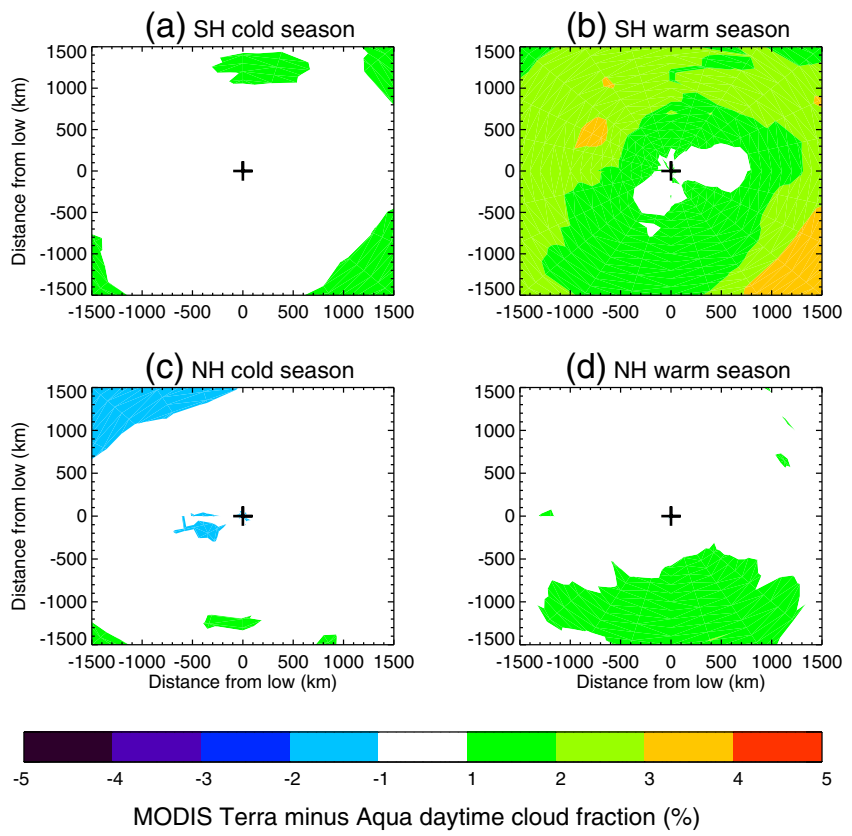

Figure 5. Difference in cyclone-centered cloud fraction composite between MODIS-Terra and MODIS-Aqua for (a) SH cold season, (b) SH warm season, (c) NH cold season, and (d) NH warm season. 
(a) 2007-2010 minus 2007

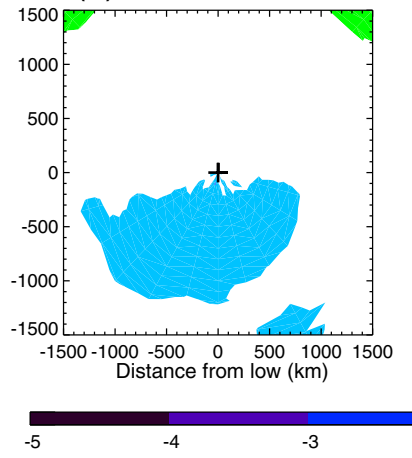

(b) Daily minus L2

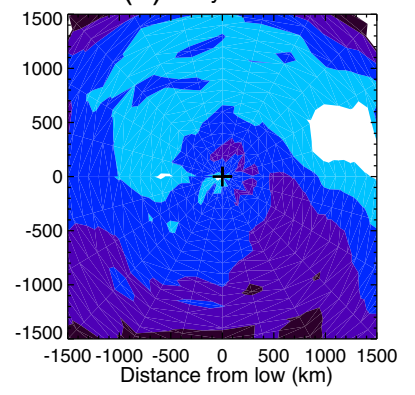

(c) Aqua: CloudSat-subset minus all

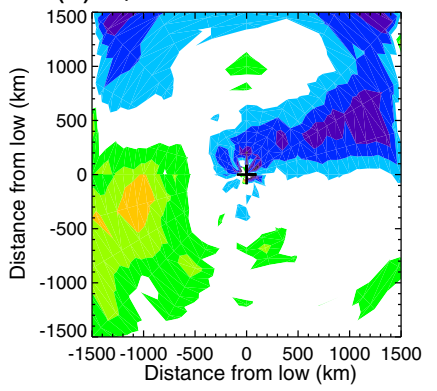

Difference in cloud fraction $(\%)$

Figure 6. Difference in cyclone-centered composite of MODIS daily cloud fraction between (a) Terra four SH cold seasons and one SH cold season, (b) Terra 2007 daily and 2007 level-2 (L2), and (c) MODIS-Aqua subsetted along CloudSat orbits and MODIS-Aqua for all observations.

level-2 files, we limit the instantaneous data set to one cold season (May to September 2007) for the entire $30^{\circ} \mathrm{S}-60^{\circ} \mathrm{S}$ midlatitude band. So, for this comparison, we calculate the daily MODIS composite using only May to September 2007 cyclones. To ensure that using only one cold season does not introduce a bias, we first analyze the difference in cloud fraction between the 2007-2010 and 2007 MODIS daily composites (Figure 6a). It shows that the 2007 cyclone cloud fractions are within $2 \%$ agreement with the four-seasons average.

[31] Figure 6b shows the difference between the daily and instantaneous (level-2) composites for 2007. The instantaneous files produce a larger cloud fraction by no more than $4 \%$ everywhere within the cyclone, with a maximum difference on the extreme poleward edge and on the equator side within the warm sector. Additionally, because these systems move quickly, and the fronts mark sharp contrasts between high and low cloud fractions, we expect the instantaneous files to have higher cloud fractions than the daily files, which can be averages of multiple observations at a single point. Interestingly, the large region with differences greater than $2 \%$ that encompasses the low and extends equatorward and eastward matches the region of the cyclone where precipitable water vapor is greatest [e.g., Field and Wood, 2007, Figure 3]. In this region, the signature of the clouds accompanying the cold front may be better defined when the cyclones and cloud observations are closer in time. As the time delay between the two increases, cold frontal cloudiness is more (a) Cloudsat-CAL minus MISR

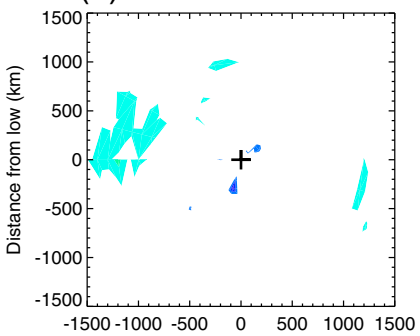

(d) same as (a) no sea ice/land

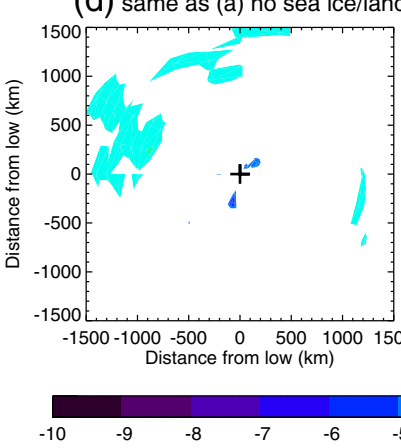

(b) MODIS minus MISR

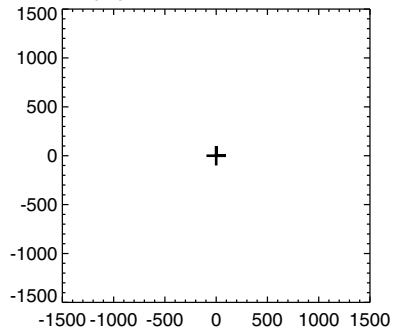

(e) same as (b) no sea ice/land

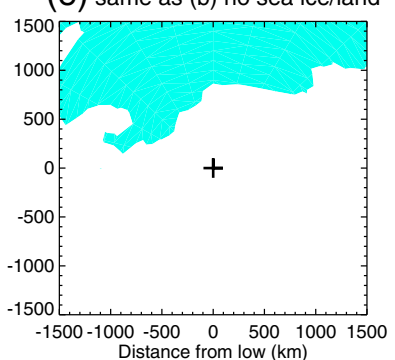

(c) MODIS minus Cloudsat-CAL

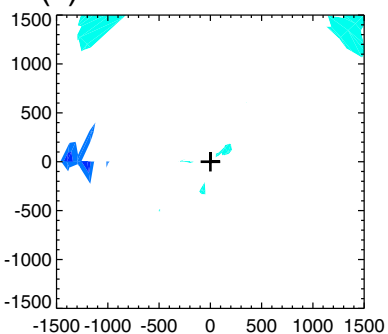

(f) same as (c) no sea ice/land
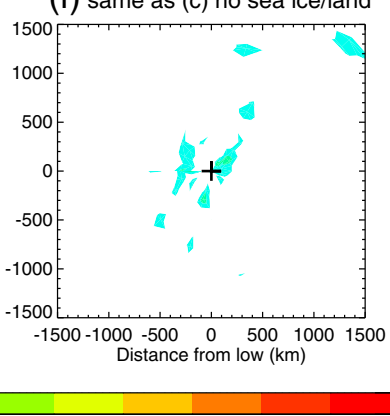

Difference in cloud fraction (\%)

Figure 7. Difference in cyclone-centered composite of SH cold season cloud fraction between (a,d) CloudSat-CALIPSO and MISR, (b,e) MODIS and MISR, and (c,f) MODIS and CloudSat-CALIPSO; Figures 7d, 7e, and 7f same as Figures 7a, 7b, and 7c without observations over sea ice and land. 
(a) Cloudsat-CAL minus MISR

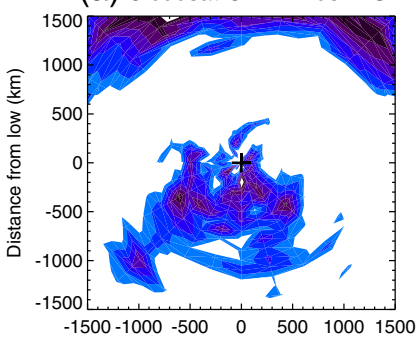

(d) same as (a) no sea ice/land

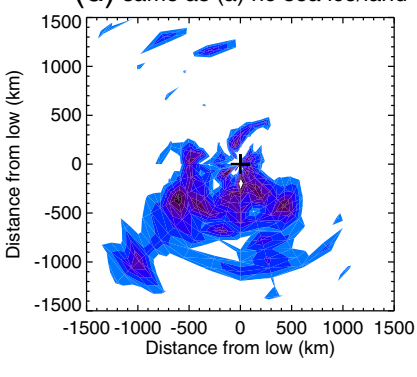

(b) MODIS minus MISR

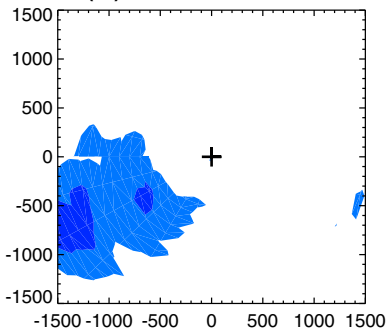

(e) same as (b) no sea ice/land

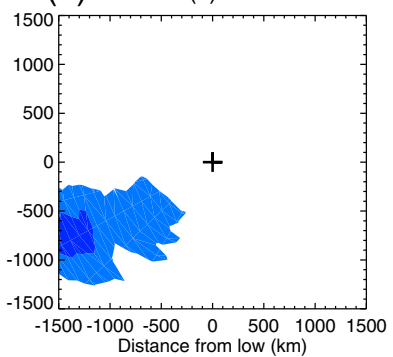

(c) MODIS minus Cloudsat-CAL

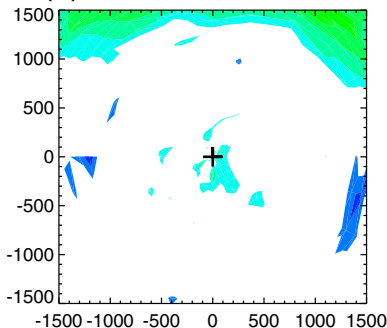

(f) same as (c) no sea ice/land

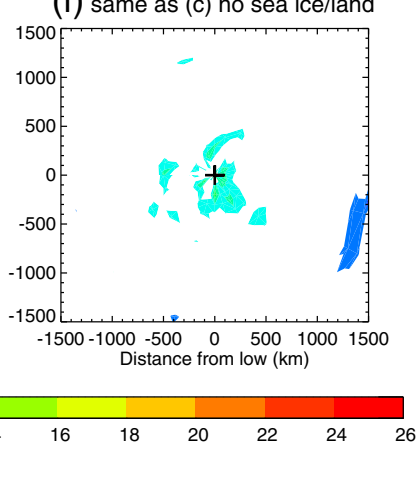

Figure 8. Difference in cyclone-centered composite of $\mathrm{SH}$ warm season cloud fraction between $(\mathrm{a}, \mathrm{d})$ CloudSat-CALIPSO and MISR, (b,e) MODIS and MISR, and (c,f) MODIS and CloudSat-CALIPSO; Figures $8 \mathrm{~d}, 8 \mathrm{e}$, and $8 \mathrm{f}$ same as Figures $8 \mathrm{a}, 8 \mathrm{~b}$, and $8 \mathrm{c}$ without observations over sea ice and land.

likely to be averaged with the low fractions found in the dry intrusion region. Consequently, the impact of the difference in time delay when comparing daily MODIS or MISR against instantaneous CloudSat-CALIPSO cloud fractions may contribute by up to $4 \%$ of the differences.

[32] Next, we sampled MODIS-Aqua daily cloud fractions along the CloudSat orbits and used these narrow paths to build the cyclone-centered composites. By testing the difference between this "CloudSat subset" composite and the composite obtained with all of the MODIS-Aqua data, we can estimate the impact of the difference in coverage of the three data sets. Figure 6c shows that the narrow CloudSat swath causes a slight overestimate in cloud fractions compared to when including the full width of the MODIS swath in the equator west quadrant $(<4 \%)$ and an underestimate along the edge of the warm front, poleward of the low, and in the pole-west quadrant $(<4 \%)$.

\section{Intercomparison Between the Three Data Sets}

[33] As exemplified in Figure 2 for the SH cold season, there are some visible differences between the data sets, such as higher cloud fractions at the extreme poleward edge of the MODIS composite or greater cloud fractions to the west of the low in the CloudSat-CALIPSO composite. In order to evaluate the magnitude of these differences, and their importance with respect to the uncertainties discussed above, we now plot and discuss the differences in daytime cloud fraction composite in the two hemispheres and two seasons. In what follows, we will examine the difference in composited cloud fractions only if they are greater than $4 \%$, as the uncertainties discussed above may explain lesser differences.

\subsection{SH Cold Season}

[34] Differences in SH cold season between the three data sets are mostly less than the $4 \%$ uncertainty referred to above (Figures 7a, 7b, and 7c). CloudSat-CALIPSO cloud fractions are slightly greater than the other two data sets in a small region to the west of the cyclone center (Figures 7a and 7c). This small difference is expected if optically thin clouds occur with no other (thicker) clouds present, due to the ability of CALIPSO to detect optically thin clouds beyond the detectability threshold of both passive instruments and the radar. Marchand et al. [2010] reviewed both MISR and MODIS strengths and weaknesses for cloud detection and height assignment and reported that both instruments have difficulty detecting thin clouds of optical depth less than 0.4 (same limit as reported in Ackerman et al. [2008] for MODIS). In contrast, the CALIPSO lidar can detect these clouds and will therefore report a larger overall cloud fraction [e.g., Holz et al., 2008]. There are two areas where CloudSatCALIPSO cloud fractions are lower than the other two data sets: the first is the extreme poleward edge where MODIS cloud fractions are larger than CloudSat-CALIPSO; the other comprises the low pressure center. Most of the cyclone region shows little difference between CloudSat-CALIPSO and the other two data sets. The MISR and MODIS cloud fractions are virtually identical. The overall agreement between the three data sets is mostly within $6 \%$ cloud fraction.

\subsection{SH Warm Season}

[35] We next explore the cloud fraction differences during the warm season (NDJFM) SH cyclones (Figure 8). Two main areas in the cyclones display differences of up to $10 \%$ and $18 \%$, respectively, which is significantly greater than $4 \%$. 
(a) SH cold season

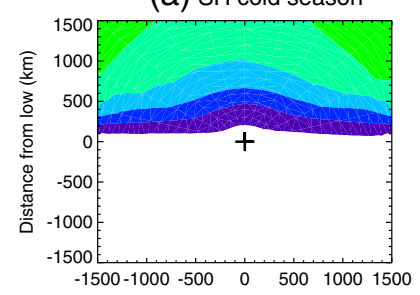

(c) $\mathrm{NH}$ cold season

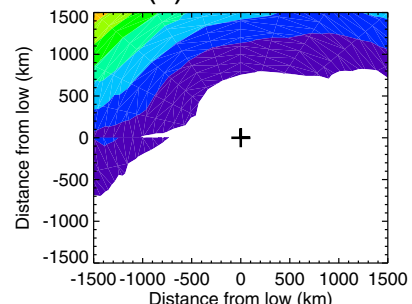

Distance from low $(\mathrm{km})$

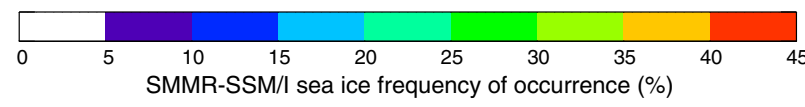

Figure 9. Composite of the frequency of occurrence of sea ice in (a) $\mathrm{SH}$ cold season, (b) $\mathrm{SH}$ warm season, (c) $\mathrm{NH}$ cold season, and (d) NH warm season daytime cyclones, obtained with sea ice concentrations measured with the SMMR-SSM/I instruments for 2007-2010. Only daytime cyclones are included.

[36] Figures 8a and 8b show larger MISR cloud fractions on the west-equatorward side of the cyclones when compared with the other two data sets. If this region is predominantly populated by cumuli, MISR may overestimate cloud fractions compared to the other two data sets [Zhao and Di Girolamo, 2006] or these clouds are too close to the surface for CloudSat-CALIPSO to be able to detect them properly [e.g., Huang et al., 2012]. Zhao and Di Girolamo [2006] demonstrate that cloud fractions are strongly dependent on the resolution at which the cloud detection is performed and on the decision made for partially filled pixels. They find that in cumulus regions, MODIS cloud fractions are systematically lower than MISR cloud fractions. The CloudSat-CALIPSO product is at $2.5 \mathrm{~km}$ resolution, thus should give even greater cloud fractions than MISR and MODIS in situations where there are broken clouds (i.e., partially filled pixels). However, if clouds are at low level, the radar may not detect them, and so the lidar is used instead. The CALIPSO cloud detections are at $0.3 \mathrm{~km}$ horizontal resolution and a cloud is detected if at least $50 \%$ of a radar volume displays a cloud signal. This implies that in this case the resolution for cloud detection is $1.2 \mathrm{~km}$, similar to the other two instruments. Consequently, the resolution at which the cloud detection is performed does not explain the difference between CloudSat-CALIPSO and MISR cloud fraction. It is possible that both the radar and the lidar have difficulty detecting low-level clouds during the day (the lidar signal-to-noise ratio is larger during the day and may cause clouds to be confused with aerosols, [e.g., Holz et al. 2008]).

[37] In contrast, the poleward edge area displays lower MISR cloud fractions than CloudSat-CALIPSO (Figure 8a) while Figure 8c suggests that MODIS displays higher cloud

fractions on the poleward edge of the cyclones than CloudSat-CALIPSO. Figure 9 reveals that the poleward edge of the SH warm season cyclones is over sea ice about $20 \%$ of the time, and Figure 10 reveals that it is also over land up to $30 \%$ of the time. According to Di Girolamo et al. [2010], MISR cloud fractions over land can display a low bias of about $7 \%$. Figures $8 \mathrm{~d}, 8 \mathrm{e}$, and $8 \mathrm{f}$ show the three difference composites over open ocean only (no sea ice or data from over land). The large differences on the poleward edge of the cyclones largely disappear over open ocean. CloudSatCALIPSO cloud fractions are not expected to be affected by the presence of sea ice for cloud detection; therefore, Figure 8d suggests that MISR cloud fractions are underestimated over sea ice and land. Surprisingly, SH cold season cyclones did not exhibit such discrepancies, and yet sea ice occurs more often on the poleward edge of the SH cold season cyclones (Figure 9). Figures 7c, 7d, and 7e show the differences for the SH cold season between the three data sets over open ocean, for consistency with Figures 8d, 8e, and $8 \mathrm{f}$. Because removing the data points over sea ice and land in the SH cold season has little effect, we suspect that the larger differences in $\mathrm{SH}$ warm season in the poleward region of the cyclones may be related to the presence of land.

[38] In any case, by restricting our comparison to open ocean, we find that the largest discrepancy is in the west-equator quadrant for the $\mathrm{SH}$ warm season, which we discussed in the prior paragraph.

\subsection{NH Cold Season}

[39] We next perform similar comparisons for northern hemisphere cyclones, only selecting those that were detected over the oceans, for consistency with the southern hemisphere cyclones analysis. Because the overall cloud spatial distribution in $\mathrm{NH}$ cyclones is similar to the $\mathrm{SH}$ cyclones,

(a) SH cold season

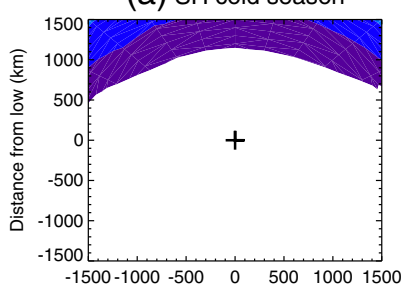

(c) $\mathrm{NH}$ cold season
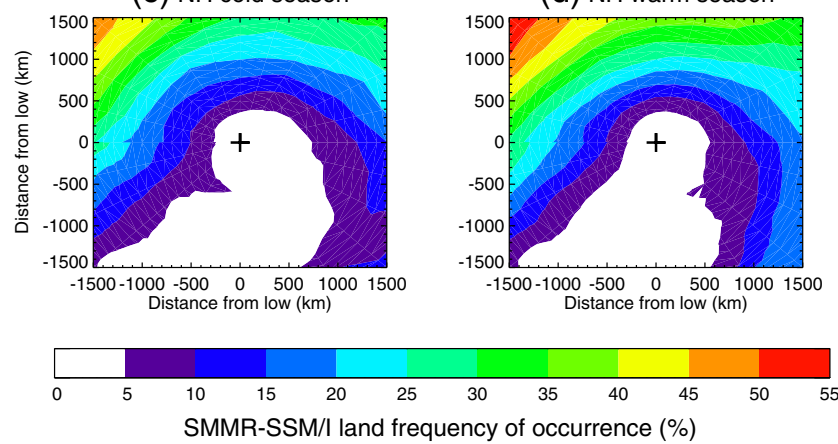

Figure 10. Cyclone-centered composites of land cover from the SMMR-SSM/I daily files for (a) SH cold season, (b) $\mathrm{SH}$ warm season, (c) NH cold season, and (d) NH warm season daytime cyclones during 2006-2010. Only daytime cyclones are included. 
(a) Cloudsat-CAL minus MISR

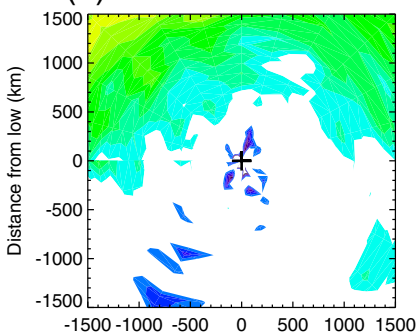

(d) same as (a) no sea ice/land

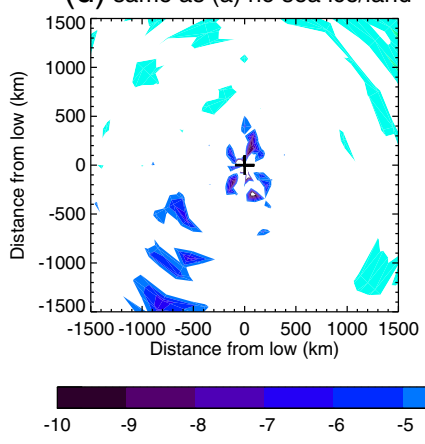

(b) MODIS minus MISR

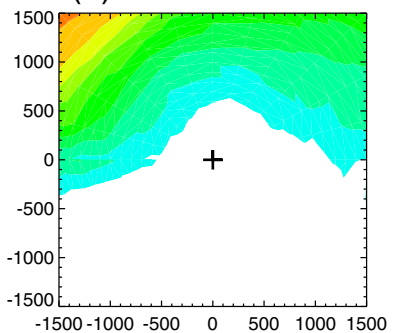

(e) same as (b) no sea ice/land

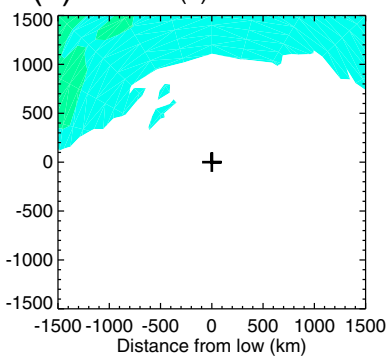

(c) MODIS minus Cloudsat-CAL

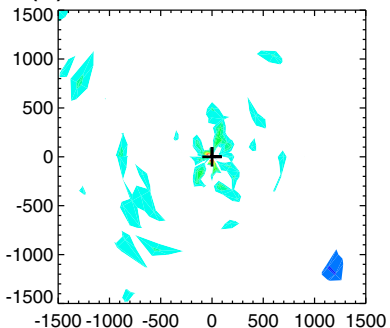

(f) same as (c) no sea ice/land

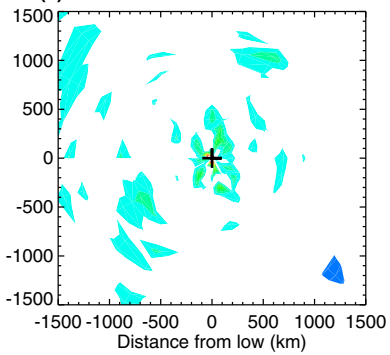

Distance from low $(\mathrm{km})$

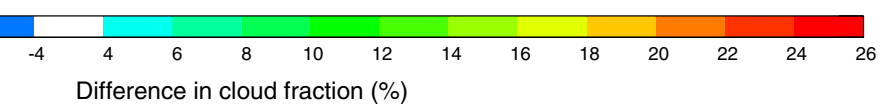

Figure 11. Difference in cyclone-centered composite of $\mathrm{NH}$ cold season cloud fraction between $(\mathrm{a}, \mathrm{d})$ CloudSat-CALIPSO and MISR, (b,e) MODIS and MISR, and (c,f) MODIS and CloudSat-CALIPSO; Figures 11d, 11e, and 11f same as Figures 11a, 11b, and 11c but without observations over sea ice and land.

we only look at differences in cloud fraction between the three data sets. Note that there are interhemispheric differences, but these have already been discussed in detail in Naud et al. [2012]. For the NH, the cold season is from November to March.

[40] Figure 11 shows the difference in daytime cloud fraction between each pair of data sets for $\mathrm{NH}$ cold season cyclones. Two regions of the cyclones exhibit differences greater than $4 \%$ : in the equator-west quadrant including the low pressure center, and on the poleward edge.

[41] Slightly larger MISR than CloudSat-CALIPSO cloud fractions are found in a small zone in the west-equator quadrant (Figure 11a). Also, Figure 11c reveals a reasonable agreement between MODIS and CloudSat-CALIPSO cloud fractions, with slightly lower CloudSat-CALIPSO cloud fractions in various places, up to $8 \%$ lower in the vicinity of the low pressure center. Figures 11a and 11c suggest that CloudSat-CALIPSO cloud fractions are lower than the other two data sets in the equator-western edge of the cyclones. This can be caused by the difference in resolution and sensitivity to low-level broken clouds between the instruments (see $\mathrm{SH}$ warm season discussion).

[42] Figures 10a and 10b reveal much lower MISR cloud fractions on the poleward side of the cyclones than the other two data sets but fairly good agreement for most of the rest of the cyclones. Although land is present sometimes on the poleward edge of the SH cyclones, it is much more prominent in the NH composites (Figure 10). Figures 11d, 11e, and $11 \mathrm{f}$ show the same differences where both land and sea ice are absent. Figures $11 \mathrm{~d}$ and $11 \mathrm{f}$ indicate that over open ocean, MISR and MODIS cloud fractions are in fairly good agreement with CloudSat-CALIPSO on the poleward side of the cyclone, although we note that MODIS cloud fractions there are slightly (less than 6\%) greater than MISR cloud fraction, which is also true for $\mathrm{SH}$ cold season (Figure 7e).

\subsection{NH Warm Season}

[43] Next, we examine the differences in data set composites for NH warm season cyclones (Figure 12). Figures 12a and 12b show a lower MISR cloud fraction on the poleward side of the cyclones, but the contrast with the other two data sets is not as large as for NH cold season composites. Because cyclones tend to occur in closer proximity to land in the warm season, we suspect that the larger winter differences may be caused by the presence of snow. Unfortunately we do not have snow cover information. In any case, when removing both land and sea ice data points, this bias disappears (Figures $12 \mathrm{~d}$ and 12e). Figure 12c suggests that MODIS cloud fractions may also be underestimated in these regions but similarly to MISR, open ocean differences do not show this bias (Figure 12f).

[44] Figures 12a and 12c indicate a tendency for CloudSatCALIPSO cloud fractions to be lower than MISR and MODIS close to the low-pressure center. It is possible that this zone is often populated by broken low-level clouds. Figures $12 \mathrm{~b}$ and $12 \mathrm{c}$ indicate that in the warm sector of summer NH cyclones, i.e., in the equator-eastern quadrant, MODIS cloud fractions are lower than in the other two data sets. The reason for this discrepancy is unclear as this region is not affected by sea ice or snow, nor by land (Figures 12e and 12f).

\subsection{Day and Night Comparison Between MODIS and CloudSat-CALIPSO}

[45] So far we restricted the comparison to daytime only observations, because that is when MISR is available. However, MODIS and CloudSat-CALIPSO have the ability to detect clouds during both day and night. Here we therefore 
(a) Cloudsat-CAL minus MISR

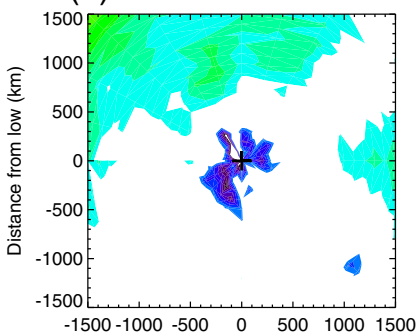

(d) same as (a) no sea ice/land

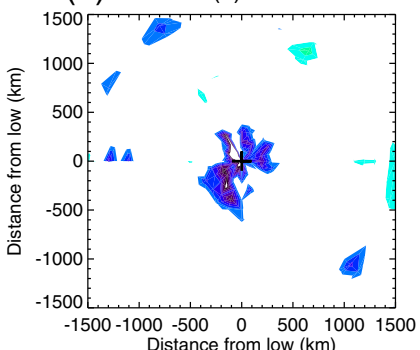

Distance from low $(\mathrm{km})$ (b) MODIS minus MISR

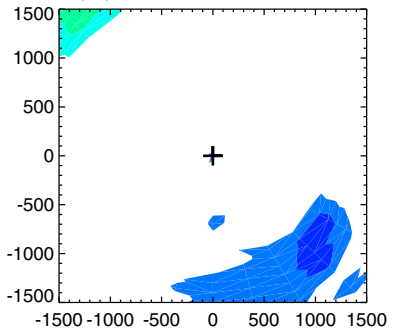

(e) same as (b) no sea ice/land

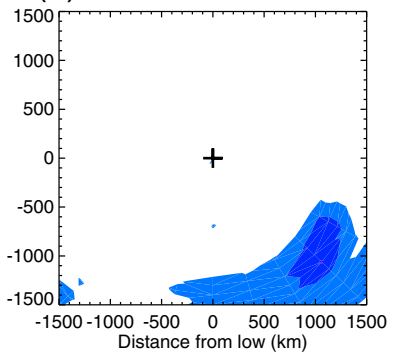

(c) MODIS minus Cloudsat-CAL

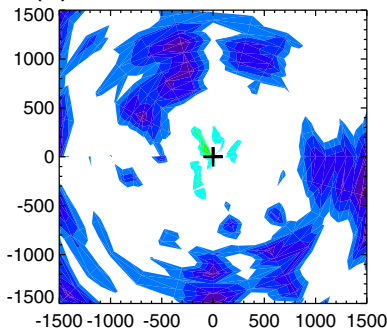

(f) same as (c) no sea ice/land

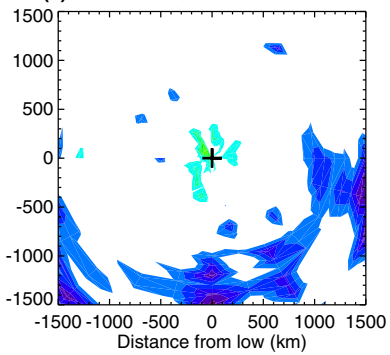

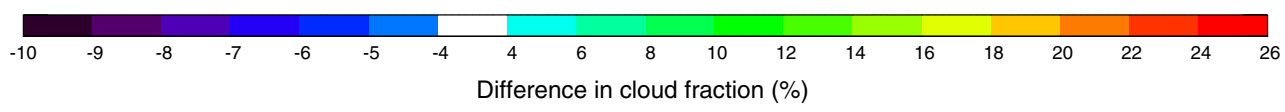

Figure 12. Difference in cyclone-centered composite of NH warm season cloud fraction between (a,d) CloudSat-CALIPSO and MISR, (b,e) MODIS and MISR, and (c,f) MODIS and CloudSat-CALIPSO; Figures 12d, 12e, and $12 \mathrm{f}$ same as Figures 12a, 12b, and 12c but without observations over sea ice and land.

want to examine if the differences between the two data sets change when nighttime observations are included. For this final test, we use MODIS-Aqua. Figure 13 shows these differences for the two hemispheres and seasons. Figure 13a indicates that MODIS cloud fractions are lower than CloudSat-CALIPSO cloud fractions on the poleward side of the $\mathrm{SH}$ cold season cyclones, presumably because MODIS may have difficulty detecting clouds at night over snow and sea ice [Ackerman et al., 2008]. Figure 13b indicates that in the SH warm season this problem disappears, but that instead MODIS cloud fractions are lower than CloudSat-CALIPSO cloud fractions on the eastern edge of the equator side of the cyclones. We find that this problem is of much smaller magnitude when using MODIS-Terra than MODIS-Aqua and when we include nighttime data. Ackerman et al. [2008] reported larger MODIS-Aqua than MODIS-Terra cloud fractions over the oceans, which somewhat contradicts what we find within extratropical cyclones. Figure $13 \mathrm{c}$ indicates that as with the SH cold season, the poleward edge of the cyclones for $\mathrm{NH}$ cold season displays lower MODIS cloud fractions than CloudSat-CALIPSO. Because this discrepancy is quite localized and does not occur during the day, it is possible that this could be caused by issues over bright surfaces at night. Figure $13 \mathrm{~d}$ shows the largest differences, as MODIS cloud fractions are lower than CloudSat-CALIPSO both on the poleward and the equatorward sides of the NH warm season cyclones. The patterns resemble those obtained with daytime data (Figure 12c), but the magnitude of the difference is larger. We interpret this as meaning that MODIS night-time detections may not be as good as daytime detections. Overall, the two data sets agree within $6 \%$ cloud fraction, with the exception of the NH warm season, where differences are closer to $10 \%$.

\section{Seasonal Contrast in the Two Hemispheres}

[46] With these discrepancies in mind, we now examine the difference in composites between cold and warm seasons, separately for each hemisphere and data set. The summer (a) $\mathrm{SH}$ cold season

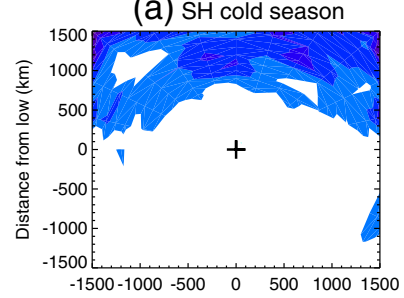

(c) $\mathrm{NH}$ cold season

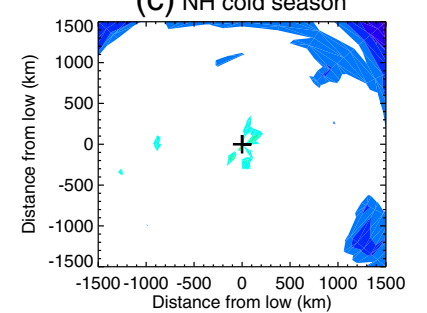

Distance from low (km)

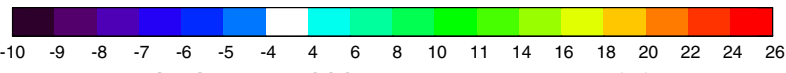

MODIS-Aqua vs CSC day+night cloud fraction (\%)
Figure 13. Difference in cyclone-centered composite of cloud fraction between MODIS-Aqua and CloudSatCALIPSO (CSC) for day and nighttime observations for (a) $\mathrm{SH}$ cold season, (b) SH warm season, (c) NH cold season, and (d) NH warm season. 
(a) SH MODIS

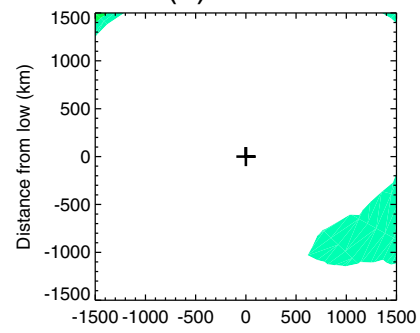

(d) same as (a) no sea ice/land

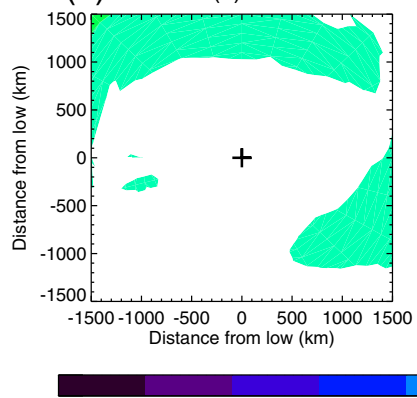

(b) SH MISR

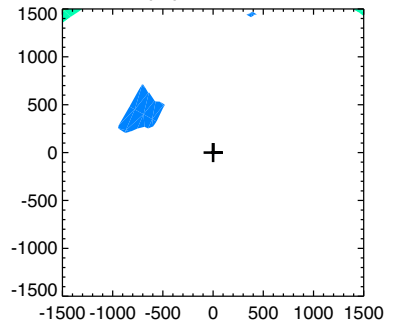

(e) same as (b) no sea ice/land

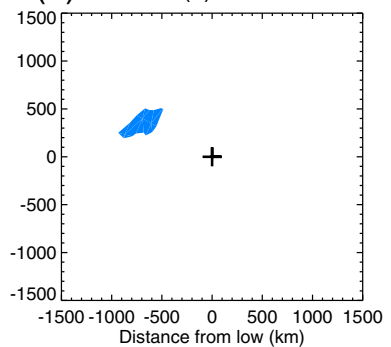

(c) SH Cloudsat-CAL

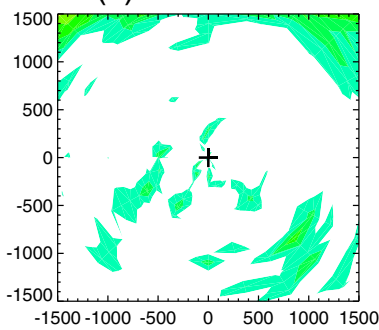

(f) same as (c) no sea ice/land

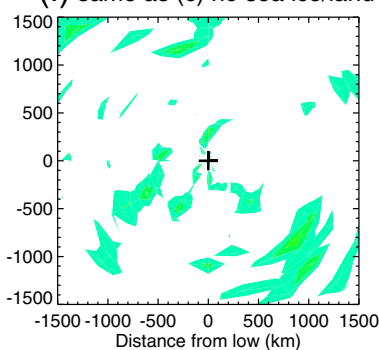

$-14$

$-12$

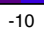

$-8$

Winter minus summer cloud fraction (\%)

Figure 14. Difference in SH cyclone-centered composite of cloud fraction between cold and warm season using (a,d) MODIS, (b,e) MISR, and (c,f) CloudSat-CALIPSO for all data points and without observations over sea ice and land.

hemispheres are expected to have more moisture available to the cyclones, while the winter cyclones are expected to be dynamically more vigorous. This could affect cloudiness on the equator-eastern side of the cyclones where the warm conveyor belt participates in cloud formation [e.g., Field and Wood, 2007; Naud et al., 2012].

[47] Here we want to demonstrate how the lessons learned from comparisons performed in the previous section improve our analysis of the seasonal differences. Figure 14 shows the difference in cloud fraction between the cold and warm seasons for $\mathrm{SH}$ and the three data sets. Figure 14a shows the cold-warm seasonal contrast in cloud fractions for MODIS, Figure $14 \mathrm{~b}$ for MISR, and Figure $14 \mathrm{c}$ for CloudSatCALIPSO, using all of the data points. The seasonal contrasts for the three data sets differ on the poleward edge of the cyclone: MODIS and MISR show virtually no contrast at all, and CloudSat-CALIPSO shows a slight contrast on the poleward edge. However, if we only consider the data points that were found over open ocean, MODIS and CloudSatCALIPSO both show that the cloud fractions are slightly greater during the cold than warm season on the poleward edge of the cyclones, as well as in the equator-east quadrant.

[48] The comparison between the three data sets reveals weaknesses that can be taken into account and add confidence in the difference plots studied here. Therefore, we examine the seasonal cold-warm season difference in cloud fraction in NH cyclones according to the three data sets when removing observations over land and sea ice. Figure 15 reveals that, for all three data sets, cold season cloud fractions are greater than their warm season counterparts in the eastern-equatorward side of the cyclones, at a distance of about $1000 \mathrm{~km}$ of the low. For distances less than $1000 \mathrm{~km}$ away (a) NH MODIS no sea ice/land
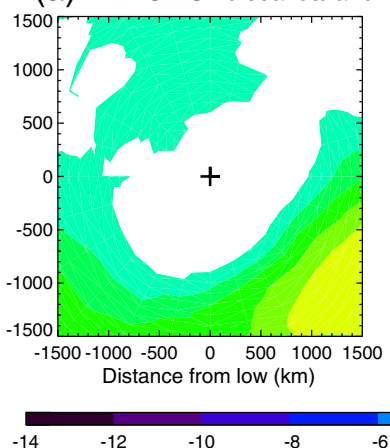

(b) NH MISR no sea ice/land

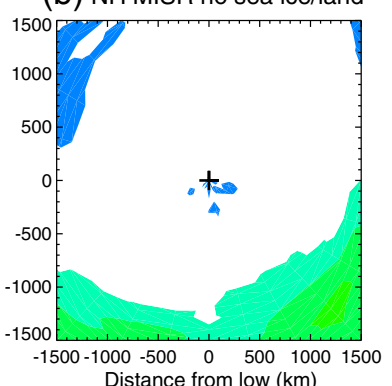

(c) NH Cloudsat-CALIPSO no sea ice/land

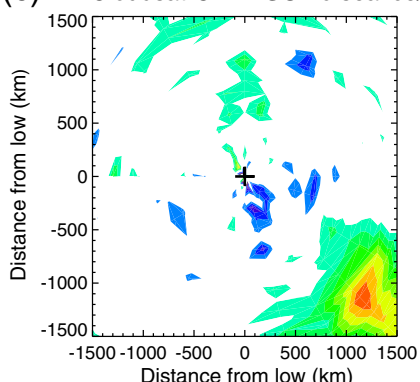

Distance from low $(\mathrm{km})$

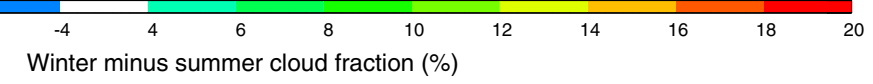

Figure 15. Difference in NH cyclone-centered composite of cloud fraction between cold and warm season using (a) MODIS, (b) MISR, and (c) CloudSat-CALIPSO with observations over sea ice and land removed. 
(a) SH PWV

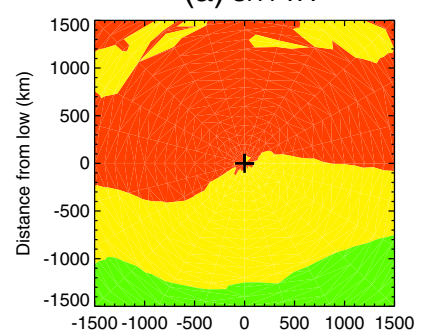

(d) NH PWV

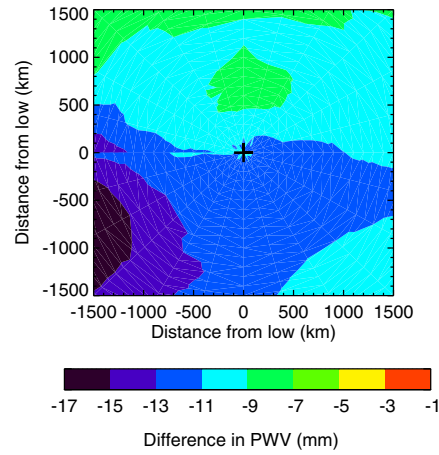

(b) SH $850 \mathrm{hPa}$ wind

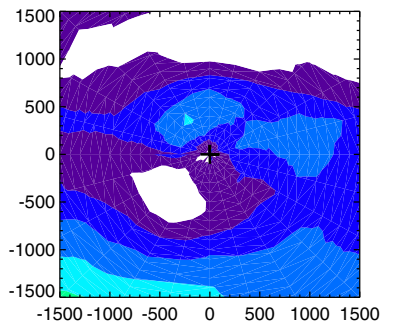

(e) $\mathrm{NH} 850 \mathrm{hPa}$ wind

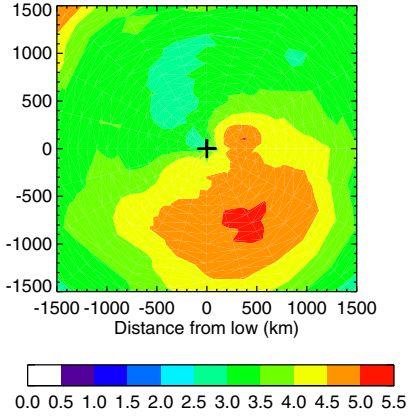

Difference in $850 \mathrm{hPa}$ wind $\left(\mathrm{ms}^{-1}\right)$ (c) SH moisture flux

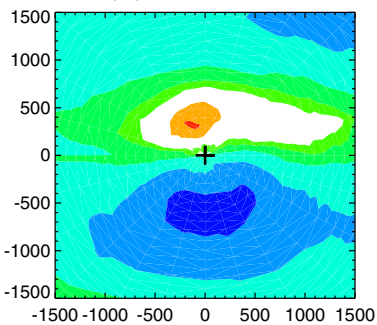

(f) $\mathrm{NH}$ moisture flux

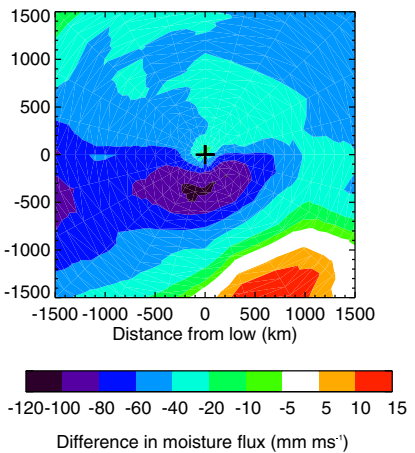

Figure 16. Difference between cold and warm season SH and NH cyclone composites of (a,d) AMSR-E PWV, (b,e) MERRA $850 \mathrm{hPa}$ wind, and $(\mathrm{c}, \mathrm{f})$ moisture flux (product of AMSR-E PWV and MERRA winds), without sea ice and land data.

from the low, MISR and CloudSat-CALIPSO both show that cold season cyclones have lower cloud fractions to the south and east of the low. Poleward of the low, MODIS and CloudSat-CALIPSO exhibit slightly larger cloud fractions in cold than warm season. This exercise allows us to conclude that cloud fractions in both hemisphere cyclones exhibit some seasonal contrast but in different regions of the cyclones. We thus explore possible reasons for the seasonal contrast and the hemisphere differences.

[49] Field and Wood [2007] found significant correlations between high cloud fractions and both column integrated precipitable water and cyclone strength in extratropical cyclones. In other words, vigorous cyclones (in terms of surface wind speed) and/or moist cyclones tend to have overall greater cloud fractions than weaker or drier cyclones. In summer, cyclones will tend to have access to more moisture than cold season cyclones, while cold season cyclones will tend to be more vigorous than warm season cyclones (in part due to the larger temperature contrast between the equator and poles).

[50] To examine the most likely cause of the interseasonal cloud differences in the warm sector, we exploit Field and Wood [2007]'s results that cloud fractions are strongly dependent on moisture amount and cyclone strength. Therefore, we create cold-warm season difference composites of AMSR-E PWV and MERRA $850 \mathrm{hPa}$ winds and moisture flux (AMSR-E PWV times MERRA winds) (Figure 16). Figures 16a and $16 \mathrm{~d}$ confirm that warm season cyclones are wetter than cold season cyclones, but they also show that the contrast is much less in $\mathrm{SH}$ than $\mathrm{NH}$ cyclones, and that the largest differences occur in different zones of the cyclones in both hemispheres. They also demonstrate that the maximum contrast occurs on the equator side of the cyclones. Figures $16 \mathrm{~b}$ and $16 \mathrm{e}$ on the other hand confirm that indeed cyclones are more vigorous during the cold than warm season (using $850 \mathrm{hPa}$ winds as a proxy for cyclone strength, [e.g., Naud et al., 2012]). Again the seasonal contrast is much less in SH than $\mathrm{NH}$ cyclones, and is greatest in slightly different places within the cyclones.

[51] Figures 16c and 16c show the difference in moisture flux between the cold and warm seasons. The $\mathrm{SH}$ and $\mathrm{NH}$ distributions of the seasonal contrast in moisture flux are also different. In the SH cyclones, the moisture flux is larger in the warm season than cold season on the equator side of the cyclones, while the opposite is true in a $500 \mathrm{~km}$ wide band poleward of the low. In the NH cyclones, the moisture flux is greater in the warm season on the poleward side of the cyclones, but changes from west to east on the equator side: moisture flux is greater during the warm than cold season to the west, while it is lower to the east. There is no clear correlation between a change in moisture flux and change in cloud fraction in the SH cyclones, but there is such a correlation in the warm sector of the NH cyclones. There is some colocation between the lower cold season cloud fractions and the lower moisture flux just southeast of the low, while the greater cloud fractions to the extreme southeast during the cold season coincide with a region where the moisture flux is greater during the cold season. In the southeast quadrant, the correlation coefficient between the moisture flux difference and the cloud fraction difference is $0.86,0.87$, and 0.74 for MODIS, MISR, and CloudSat-CALIPSO, respectively. This suggests that, at least in the warm sector, greater winds in NH cold season cyclones overcompensate for the loss of moisture, thereby allowing for more clouds to form.

\section{Conclusions}

[52] We composite daytime cloud fraction within extratropical cyclones over northern and southern hemisphere 
oceans during the cold and warm seasons using three different instruments and associated cloud fraction retrievals: MODIS, MISR, and CloudSat-CALIPSO. NH and SH cold and warm season cyclones display cloud fractions of at least $70 \%$ in most of the cyclonic region, with a maximum above $90 \%$ at the central low and along the warm frontal region. Cloud fractions decrease away from the low, with minima at the extreme poleward edge and on the equator side.

[53] Despite the differences in temporal and spatial resolution, instrument type, and retrieval techniques, the cyclonecomposited cloud fractions closely agree across the three data sets, barring a few isolated regions in which differences are still no larger than $10 \%$. The intercomparison reveals a tendency for both MODIS and MISR cloud fractions to differ from each other and from CloudSat-CALIPSO in areas where sea ice and land are most often present. At the back and along the cold frontal regions of the cyclones, CloudSat-CALIPSO cloud fractions are lower than the other two data sets, while MISR cloud fractions are largest in the $\mathrm{SH}$ warm season.

[54] The differences between cold and warm season cloud fractions in $\mathrm{SH}$ cyclones are confined to within $10 \%$ and as such are not significantly larger than the inter-data set disagreement in both seasons. This is in part due to a low seasonal contrast in moisture amount and $850 \mathrm{hPa}$ wind speed. In contrast, NH cyclones display a much larger difference between cold and warm season moisture amount, low-level wind speed, and cloud fractions. According to both MISR and CloudSat-CALIPSO, cold season NH cyclones have fewer clouds close to the system low in the warm sector, where the $850 \mathrm{hPa}$ moisture flux is less in the cold season as compared to the warm season. In contrast, NH cold season cyclones display larger cloud fractions toward the equatorward edge of the composites, according to all three data sets, which can be attributed to a larger moisture flux in this region. We thus conclude that seasonal variations in cyclone cloud fractions exhibit an interhemispheric asymmetry: changes in the NH are significant, while those in the $\mathrm{SH}$ are weak.

[55] Uncertainties in all three data sets are lowest in the warm sector and along the warm frontal region. On the poleward side of the cyclones, cloud fractions are more uncertain when cyclones travel over sea ice or land, but are fairly consistent over open ocean. One region of the cyclones that warrants closer examination and further work is the westernequatorward quadrant, i.e., the region behind cold fronts. These cloud fraction composites can be used to evaluate general circulation models, whether they output cloud fractions using the COSP instrument simulators [Bodas-Salcedo et al., 2011] or not. Although the synergy between the two active instruments CloudSat and CALIPSO probably provides the best estimate of observed cloud fractions in the mean, the lack of surface-based observations in the southern oceans means that it is impossible at this point to indicate which of the three data sets tested here is closest to the truth. Therefore, these results do not provide a definite error estimate in the observed cloud fraction cyclone-centered composites. Instead, they provide a reference of what the relative uncertainty might be. In fact, although none of the data sets examined here can stand alone, each having its own strengths and weaknesses, the uncertainties in the separate data sets are largely eliminated when taken together.
This study should help estimate the significance of possible discrepancies between observed and modeled cyclone cloud fraction, using all three data sets together for a more robust constraint.

[56] Acknowledgments. MODIS data were obtained from the Level 1 and Atmospheric Distribution System at the NASA Goddard Space Flight Center. MISR data files were obtained from the NASA Langley Atmospheric Sciences Data Center. CloudSat-CALIPSO GEOPROFLIDAR data were obtained from the CloudSat Data Processing Center. The SMMR-SSM/I daily sea ice concentration and AMSR-E data were obtained from the National Snow and Ice Data Center. MERRA files were obtained from the NASA Goddard Earth Sciences Data and Information Services Center. This work was funded by NASA CloudSat Science team grant NNX10AM20G and NASA the Science of Terra and Aqua grant NNX11AH22G. The authors thank Larry Di Girolamo for his extremely useful comments, and the editor along with three anonymous reviewers for significantly improving the quality of the manuscript.

\section{References}

Ackerman, S. A., R. E. Holz, R. Frey, E. W. Eloranta, B. C. Maddux, and M. McGill (2008), Cloud detection with MODIS. Part II: Validation, J. Atmos. Oceanic Technol., 25, 1073-1086.

Bauer, M., and A. D. Del Genio (2006), Composite analysis of winter cyclones in a GCM: Influence on climatological humidity, J. Clim., 19, $1652-1672$.

Bodas-Salcedo, A., et al. (2011), COSP Satellite simulation software for model assessment, Bull. Am. Meteorol. Soc., 92, 1023-1043.

Bodas-Salcedo, A., K. D. Williams, P. R. Field, and A. P. Lock (2012), The surface downwelling solar radiation surplus over the southern ocean in the Met Office model: The role of midlatitude cyclone clouds, J. Clim., 25, 7467-7486.

Booth, J. F., C. M. Naud, and A. D. Del Genio (2013), Diagnosing warm frontal cloud formation in a GCM: A novel approach using conditional subsetting, J. Clim., 26, 5827-5845, doi:10.1175/JCLI-D-12-00637.1.

Carlson, T. N. (1980), Airflow through midlatitude cyclons and the comma cloud pattern, Mon. Weather Rev., 108, 1498-1509.

Catto, J. L., L. C. Shaffrey, and K. I. Hodges (2010), Can climate models capture the structure of extratropical cyclones?, J. Clim., 23, 1621-1635.

Cavalieri, D., C. Parkinson, P. Gloersen, and H. J. Zwally (1996), Sea ice concentrations from Nimbus-7 SMMR and DMSP SSM/I-SSMIS Passive Microwave Data, [Final data], updated yearly, National Snow and Ice Data Center, Boulder, Colo.

Dee, D. P., et al. (2011), The ERA-Interim reanalysis: Configuration and performance of the data assimilation system, Q. J. R. Meteorol. Soc., 137, 553-597.

Di Girolamo, L., and M. J. Wilson (2003), A first look at band-differenced angular signatures for cloud detection from MISR, IEEE Trans. Geosci. Remote Sens., 41, 1730-1734.

Di Girolamo, L., A. Menzies, G. Zhao, K. Mueller, C. Moroney, and D. J. Diner (2010), Level 3 cloud fraction by altitude algorithm theoretical basis, JPL D-62358.

Diner, D. J., et al. (1998), Multi-Angle Imaging Spectro-radiometer (MISR) description and experiment overview, IEEE Trans. Geosci. Remote Sens., 36, 1072-1087.

Diner, D. J., R. Davies, L. Di Girolamo, A. Horvath, C. Moroney, J.-P. Muller, S. R. Paradise, D. Wenkert, and J. Zong (1999), Level 2 cloud detection and classification algorithm theoretical basis, JPL D-11399, Rev. D.

Field, P. R., and R. Wood (2007), Precipitation and cloud structure in midlatitude cyclones, J. Clim., 20, 233-254.

Field, P. R., A. Gettelman, R. B. Neale, R. Wood, P. J. Rasch, and H. Morrison (2008), Midlatitude cyclone compositing to constrain climate model behavior using satellite observations, J. Clim., 21, 5887-5903.

Field, P. R., A. Bodas-Salcedo, and M. E. Brooks (2011), Using model analysis and satellite data to assess cloud and precipitation in midlatitude cyclones, Q. J. R. Meteorol. Soc., 137, 1501-1515, doi:10.1002/qj.858.

Govekar, P. D., C. Jakob, M. J. Reeder, and J. Haynes (2011), The threedimensional distribution of clouds around Southern Hemisphere extratropical cyclones, Geophys. Res. Lett., 38, L21805, doi:10.1029/ 2011GL049091.

Haynes, J. M., C. Jakob, W. B. Rossow, G. Tselioudis, and J. Brown (2011), Characteristics of southern ocean cloud regimes and their effects on the energy budget, J. Clim., 24, 5061-5080.

Holz, R. E., S. A. Ackerman, F. W. Nagle, R. Frey, S. Dutcher, R. E. Kuehn, M. A. Vaughan, and B. Baum (2008), Global Moderate resolution Imaging Spectroradiometer (MODIS) cloud detection and height 


\section{NAUD ET AL.: MULTIPLE CYCLONE CLOUD FRACTION OBSERVATIONS}

evaluation using CALIOP, J. Geophys. Res., 113, D00A19, doi:10.1029/ 2008JD009837.

Huang, Y., S. T. Siems, M. J. Manton, L. B. Hande, and J. M. Haynes (2012), The structure of low-altitude clouds over the Southern Ocean as seen by CloudSat, J. Clim., 25, 2535-2546.

Igel, A. L., S. C. van den Heever, C. M. Naud, S. M. Saleeby, and D. J. Posselt (2013), Sensitivity of warm frontal processes to cloud-nucleating aerosol concentrations, J. Atmos. Sci., 70, 1768-1783.

Kawanishi, T., T. Sezai, Y. Ito, K. Imaoka, T. Takeshima, Y. Ishido, A. Shibata, M. Miura, H. Inahata, and R. W. Spencer (2003), The Adanced Microwave Scanning Radiometer for the Earth Observing System (AMSR-E), NASDA's contribution to the EOS for global energy and water cycle studies, IEEE Trans. Geosci. Remote Sens., 41, 184-194.

Klein, S. A., and C. Jakob (1999), Validation and sensitivities of frontal clouds simulated by the ECMWF model, Mon. Weather Rev., 127, 2514-2531.

Lau, N.-C., and M. W. Crane (1995), A satellite view of the synoptic-scale organization of cloud properties in midlatitude and tropical circulation systems, Mon. Weather Rev., 123, 1984-2006.

Mace, G. G., Q. Zhang, M. Vaughan, R. Marchand, G. L. Stephens, C. Trepte, and D. Winker (2009), A description of hydrometeor layer occurrence statistics derived from the first year of merged CloudSat and CALIPSO data, J. Geophys. Res., 114, D00A26, doi:10.1029/2007JD009755.

Mace, G. G., S. Houser, S. Benson, S. A. Klein, and Q. Min (2011), Critica evaluation of the ISCCP simulator using ground-based remote sensing data, J. Clim., 24, 1598-1612.

Marchand, R., G. G. Mace, T. Ackerman, and G. Stephen (2008), Hydrometeor detection using CloudSat - An Earth orbiting 94-GHz cloud radar, J. Atmos. Oceanic Technol., 25, 519-533.

Marchand, R., T. Ackerman, M. Smyth, and W. B. Rossow (2010), A review of cloud top height and optical depth histograms from MISR, ISCCP and MODIS, J. Geophys. Res., 115, D16206, doi:10.1029/2009JD013422.

Moroney, C., R. Davis, and J.-P. Muller (2002), Operational retrieval of cloud-top heights using MISR data, IEEE Trans. Geosci. Remote Sens., 40, 1532-1540.

Naud, C. M., A. D. Del Genio, M. Bauer, and W. Kovari (2010), Cloud vertical distribution across warm and cold fronts in CloudSat-CALIPSO data and a general circulation model, J. Clim., 23, 3397-3415, doi:10.1175/ 2010JCLI3282.1.

Naud, C. M., D. J. Posselt, and S. C. van den Heever (2012), Observational analysis of cloud and precipitation in midlatitude cyclones: Northern versus southern hemisphere warm fronts, J. Clim., 25, 5135-5151.
Pincus, R., S. Platnick, S. A. Ackerman, R. S. Hemler, and R. J. P. Hofmann (2012), Reconciling simulated and observed views of clouds MODIS, ISCCP, and the limits of instrument simulators, J. Clim., 25, 4699-4720.

Platnick, S., M. D. King, S. A. Ackerman, W. P. Menzel, B. A. Baum, J. C. Riedi, and R. A. Frey (2003), The MODIS cloud products: Algorithms and examples from Terra, IEEE Trans. Geosci. Remote Sens., 41, 459-473.

Rienecker, M. M., et al. (2011), MERRA: NASA's Modern Era Retrospective analysis for Research and Applications, J. Clim., 24 3624-3648.

Salomonson, V. V., W. L. Barnes, P. W. Maymon, H. E. Montgomery, and H. Ostrow (1989), MODIS: Advanced facility instrument for studies of the earth as a system, IEEE Trans. Geosci. Remote Sens., 27, 145-153.

Stephens, G. L., et al. (2002), The CloudSat mission and the A-TRAIN: A new dimension of space-based observations of clouds and precipitation, Bull. Am. Meteorol. Soc., 83, 1771-1790.

Trenberth, K. E., and J. Fasullo (2010), Simulation of present day and $21^{\mathrm{st}}$ century energy budgets of the southern oceans, J. Clim., 23, 440-454.

Tselioudis, G., and C. Jakob (2002), Evaluation of midlatitude cloud properties in a weather and a climate model: Dependence on dynamic regime and spatial resolution, J. Geophys. Res., 107(D24), 4781, doi:10.1029/ 2002JD002259.

Wentz, F., and T. Meissner (2004), AMSR-E/Aqua L2B Global swath ocean products derived from Wentz Algorithm V002, 2006-2009, updated daily, National Snow and Ice Data Center, Boulder, Colo. Digital media.

Williams, K. D., A. Bodas-Salcedo, M. Deque, S. Fermepin, B. Medeiros, M. Watanabe, C. Jakob, S. A. Klein, C. A. Senior, and D. L. Williamson (2013), The Transpose-AMIP II experiment and its application to the understanding of Southern Ocean cloud biases in climate models, J. Clim., 26, 3258-3274, doi:10.1175/JCLI-D-12-00429.1.

Winker, D. M., M. A. Vaughan, A. H. Omar, Y. Hu, K. A. Powell, Z. Liu, W. H. Hunt, and S. A. Young (2009), Overview of the CALIPSO mission and CALIOP data processing algorithms, J. Atmos. Oceanic Technol., 26, 2310-2323.

Zhao, G., and L. Di Girolamo (2004), A cloud fraction versus view angle technique for automatic in-scene evaluation of the MISR cloud mask, J. Appl. Meteorol., 43, 860-869.

Zhao, G., and L. Di Girolamo (2006), Cloud fraction errors for trade wind cumuli from EOS-Terra instruments, Geophys. Res. Lett., 33, L20802, doi:10.1029/2006GL027088. 